\title{
LA INVESTIGACIÓN HISTÓRICA EN ESPAÑA A TRAVÉS DE UNA OPOSICIÓN DEL CSIC*
}

\author{
por \\ horacio caper \\ Universidad de Barcelona
}

La reciente celebración de un concurso oposición para cubrir una plaza de Colaborador de Investigación en el Consejo Superior de Investigaciones Científicas, de cuyo tribunal he tenido el honor y el privilegio de formar parte, permite tener un panorama general del estado de las investigaciones que se realizan en el campo de la historia en instituciones de este centro o en relación con el mismo. La presente nota trata de comunicar a los lectores de la revista los datos fundamentales de dicho concurso y la impresión general que he obtenido durante el desarrollo de los ejercicios y con la consulta de la documentación presentada por los concursantes.

\section{El concurso y su normativa}

La plaza objeto de concurso era una de las 53 de la Escala de Colaboradores Científicos del CSIC convocadas por orden de 26 de febrero de 1996, y cuyas bases pueden leerse en el Boletín Oficial del Estado de fecha 8 de marzo. Solo seis de dichas plazas correspondian a humanidades y ciencias sociales (concretamente 2 a filologia, 1 a sociología, 1 a filosofía moderna, 1 a macroeconomia y 1 a historia) mientras que el resto se asignaban a organismos de ciencias físico-naturales y tecnología, con la siguiente distribución: biologia y biomedicina (10 plazas), recursos naturales (6), ciencias agrarias (6), ciencias y tecnologias físicas (6), ciencia y tecnología de materiales (10), ciencias y tecnologías químicas (7), e interáreas (2).

El hecho de que se tratara de una plaza de «Historia», sin especificación de perfil, indica que integraba todos los campos de la historia, desde la prehis-

* El Consejo de redacción de HISPANIA ha considerado oportuno publicar las reflexiones y el análisis del Prof. Capel sobre un reciente concurso-oposición celebrado en el C.S.I.C. a una plaza en el Centro de Estudios Históricos, porque testimonian el panorama historiográfico en España, así como las inquietudes metodológicas y expectativas profesionales de los jóvenes historiadores. 
toria a la historia contemporánea y desde la historia del arte a la historia de la ciencia. No es, desde luego, una buena medida esta unificación de todos los campos históricos, ya que sitúa al tribunal ante la necesidad de tomar unas decisiones que deberían haber sido adoptadas por los directivos del CSIC, a los que corresponde establecer las prioridades y la política de reforzamiento de líneas y equipos de investigación.

El juicio del tribunal se tiene que fundamentar en los elementos adquiridos en las dos fases de los ejercicios, a saber: la de concurso y la de oposición. La primera consiste «en la exposición oral y pública del aspirante, en el tiempo máximo de media hora, de los méritos alegados y de la labor científica desarrollada descrita en el curriculum vitae. Seguidamente el Tribunal debatirá con el aspirante, sin límite de tiempo, sobre el contenido de la exposición oral del mismo, pudiendo hacer las preguntas que considere convenientes". El tribunal puede, naturalmente, examinar antes o durante el desarrollo del ejercicio las publicaciones y los méritos alegados.

La fase de oposición, que se desarrolla a continuación consiste «en la exposición pública, durante un tiempo máximo de 50 minutos, de un tema específico de la investigación desarrollada por el aspirante, elegido libremente por él mismon, tras lo cual el tribunal puede discutir con el durante un máximo de una hora, acerca de los contenidos científicos expuestos y sobre todos aquellos aspectos que se consideren relevantes en relación con el tema.

Las normas publicadas en el B.O.E. establecen cuidadosamente la forma de evaluar los méritos de los aspirantes, disponiendo, por ejemplo, que la puntuación del primer ejercicio habrá de ser doble que la del segundo, es decir, 20 puntos frente a 10 en el segundo. En lo que se refiere a la evaluación de las publicaciones, se realiza una distinción que, sin duda responde a los criterios comúnmente aceptados en el campo de las ciencias físico-naturales y tecnología, pero que es discutible en el campo de las humanidades y ciencias sociales, a saber: la distinción entre:

«a) Trabajos originales de investigación publicados en revistas científicas.

b) Publicación o participación en la publicación de libros, monografías etc. Participación en proyectos o programas y contratos o convenios de investigación. Participación en patentes y acuerdos de cesión de tecnología, asi como en trabajos de apoyo tecnológico. Estancias en centros de investigación nacionales y extranjeros. Participación en congresos cientificos, seminarios y cursos. Formación académica del aspirante. Cualquier otro mérito que alegue»

No cabe duda que esta distinción entre artículos y libros y el realce concedido a los primeros, tiene que ver con la práctica habitual de los científicos físico-naturales, que difunden sus trabajos mediante artículos cortos publicados en revistas de reconocido prestigio, y que escasamente publican libros. Pero eso tiene poco que ver con lo que es normal en el campo de las humanidades, donde la publicación de libros es un resultado frecuente de las investigaciones y trabajos que se realizan. Así, una valoración de los criterios establecidos en la convocatoria nos conduce a una conclusión clara, la de que tal vez en el CSIC tienen una influencia desmesurada los científicos de las

Hispania, LVIJ/, núm. 195 (1997) 305-327 
ciencias físico-naturales a la hora de evaluar los méritos investigadores, y que, por eso mismo, convendria refinar dichos criterios para tener en cuenta las especificidades de las distintas ramas del conocimiento.

Se debe unir a ello una crítica de la sobrevaloración que se realiza de los artículos publicados en revistas editadas en inglés, considerada hoy justamente la lengua franca de la comunicación científica. Convendría, sin embargo, tener presente dos hechos. Uno, que las comunidades cientificas mas dinámicas y de mayor solidez, como la alemana, japonesa o rusa, se esfuerzan en valorar sus propios idiomas en la publicación de los resultados de investigación, apoyando la consolidación de publicaciones periódicas que actúen como portavoces a escala internacional (con exigentes comités de selección y los correspondientes resúmenes en varios idiomas, entre los cuales el inglés); de manera semejante debemos apoyar la consolidación de publicaciones españolas de nivel internacional escritas en castellano. Y otro, que las humanidades y las ciencias sociales pueden desempeñar, además de las funciones especificamente científicas, otras funciones culturales decisivas que deben ser tenidas también en cuenta en el apoyo institucional.

Problema difícil platea también para cualquier tribunal la evaluación de los restantes méritos de los concursantes. La presentación de una comunicación a un congreso puede ser redundante con los méritos esgrimidos en las publicaciones cuando dicha comunicación se edita. También plantea dudas la valoración relativa de la organización de congresos y seminarios, la participación activa en actividades institucionales (en este caso actividades en organismos del CSIC), o la conveniencia de apoyar a personas que están vinculados ya a dichas instituciones, frente a los que tratan de integrarse en ellas desde el exterior. Todo lo cual deja un amplio margen de discrecionalidad a los miembros de un tribunal y les obliga a tomar medidas que posteriormente afectan a las calificaciones y pueden dar lugar a reticencias y malos entendidos, aún en el caso de que -como creo que ocurrió en el tribunal a que me refiero- existiera la mejor intención en cuanto a la ecuanimidad del juicio.

\section{Los concursantes}

El tribunal de este concurso ' se enfrentó a una difícil tarea. Inicialmente aspiraban a la plaza objeto de competición unos 40 investigadores pertenecientes, vale la pena recordarlo a todos los campos de la historia. Algunos de ellos, doce en total, desistieron de presentarse realmente a las pruebas. Esos concursantes pertenecían a las áreas de prehistoria, arqueología e historia

I El tribunal estaba constituido por siete miembros; cuatro investigadores del CSIC: los Drs. Enrique Arias (Historia del arte), Agustín Guimerá (Historia moderna), Sisinio Pérez Garzón (Historia contemporánea) y Antonio Lafuente (Historia de la ciencia); dos profesores de universidad: los Drs. Javier Fernández Conde (Historia medieval) y H. Capel (Geografía humana); y tenía como presidente a un académico que reparte su actividad entre las dos instituciones, el Dr. Domingo Plácido (Historia antigua). 
antigua (3), historia medieval (2), historia moderna (2), historia contemporánea (1), historia del arte (2) e historia de la ciencia (2).

Los que realmente comparecieron a la prueba fueron finalmente 27 , una cifra verdaderamente elevada para una sola plaza, lo que convertía en dramático el acontecimiento, tanto mas si tenemos en cuenta que todos los concursantes tenían una larga experiencia investigadora y, en general, méritos suficientes para tener la plaza.

En efecto, la mayor parte de los concursantes tenían una previa experiencia investigadora, y frecuentemente una amplia labor, y estaban, además, ligados ya a instituciones del CSIC. La edad media de los que se presentaron era de 35,6 años, pero la distribución de edades muestra que algunos eran ya experimentados investigadores: 1 tenía mas de 50 años, 5 estaban en la cuarentena, 19 entre 30 y 40 años y solo dos de menos de 30 .

Aunque en un abanico tan amplio de edades pueden encontrarse una gran variedad de currículos, la carrera tipo de los participantes es la siguiente. Se trata de un investigador que tras haber realizado su licenciatura en Historia y pasar a veces algún año realizando la tesina, obtiene una beca de investigación para realizar su tesis doctoral, adscrito normalmente a algún centro de investigación del CSIC. Tras realizar dicha tesis y defenderla con gran éxito, obtiene una beca para ampliar su formación en el extranjero. Transcurridos uno o dos años, puede volver a España contando con una beca de reincorporación de doctores. Finalmente se vincula a un centro del Consejo mediante contratos de asociación o colaboración, generalmente integrándose en algún programa de investigación en marcha.

En la mayoría de los casos el tema de investigación elegido supone la necesidad de una formación complementaria. Ello puede representar un largo y pesado itinerario intelectual y académico. Por ejemplo, para un licenciado en historia que va a dedicarse a investigaciones en el campo de la prehistoria o la historia antigua o medieval, puede suponer la necesidad de formarse en materias como estadística aplicada a la arqueología, paleobotánica, botánica, paleometalurgia, técnicas de carbono 14, antracología, palinología, análisis del modelado de impresiones vegetales en cerámica o tapial, estudios de semillas con microscopios electrónicos o sedimentología y estratigrafia. En arqueología se ha hecho esencial la utilización de técnicas auxiliares y el arqueólogo se ve obligado a asociarse íntimamente con técnicos altamente especializados o a convertirse él mismo en especialista. A ello debe unirse la importancia que ha adquirido la arqueología experimental, que exige a veces el aprendizaje de técnicas artesanas (fabricación de utillaje, construciones para el almacenamiento agrícola, etc.).

De manera mas o menos semejante ocurre en los otros campos de la historia. Por ello la mayor parte de los concursantes han realizado diversos cursos de postgrado, y presentan gran número de certificados. Desde luego eso muestra el interés que tienen, pero también la necesidad, de complementar la formación universitaria inicial a través de cursos especializados. Y creo que vale la pena destacar que los licenciados que proceden del campo de las

Hispania, LVIJ/1, núm. 195 (1997) 305-327 
humanidades, no parecen haber tenido ningún problema para reciclarse y adquirir una preparación a veces bastante alejada de sus estudios iniciales.

Otras veces se trata de cursos de carácter mas general, cuya utilidad para la investigación puede no estar clara. En todo caso, resulta urgente establecer algún tipo de criterio para la calificación y evaluación de los cursos de postgrado y de los diplomas que proporciona. Es difícil a un tribunal decidir si se evalúa específicamente la realización de los citados cursos como prueba del interés por completar la formación, o si se debe prescindir de ellos y valorar, sobre todo, los resultados de los mismos en el trabajo investigador.

Un aspecto fundamental de la formación de los investigadores es la estancia en el extranjero, ligados a centros prestigiosos de formación o a equipos de investigación. Normalmente eso se realiza, como se ha dicho, a través de la obtención de becas postdoctorales.

Sin duda, se trata de un aspecto esencial que ha contribuido de forma importante a la renovación de la investigación científica española. Durante las pruebas del concurso pudo comprobarse una y otra vez la trascendencia de esa etapa, la cuidadosa y pertinente selección del centro (en general, buscando las figuras mas destacadas de cada especialidad) y la enumeración de los centros frecuentados. En Francia, ante todo París: las diversas Universidades y la Maison des Sciences de l'Homme, Ecole des Hautes Etudes donde varios concursantes citaron a Bernard Vincent- el Musée d'Histoire Naturelle, o el Institut de Peleontologie Humaine; pero también Besançon, para estudios de paisajes antiguos, catastros e intervenciones territoriales; Montpellier, con el equipo Environnement et Archéologie, y otras. En Italia, varias ciudades (Bolonia, Venecia) fueron citadas como lugar de estudio, aunque destaca por su importancia la Escuela Española de Historia y Arqueología de Roma, en relación con la cual algunos han realizado excavaciones arqueológicas en esta ciudad y en el Lacio, siendo varios los que resaltaron la importancia de los contactos mantenidos en ella y los estímulos para su formación y línea investigadora. De manera similar, otros concursantes valoraron de forma positiva sus estudios en Gran Bretaña (en la London Schools of Economics, el Instituto Warburg, o la Universidad de Essex), Holanda (Universidad de Leyden), Suiza (Universidad de Berna, grupo de estudios sobre historia del clima), o Bélgica.

Naturalmente, otro país importante para la formación de posgraduados es Estados Unidos, donde diversas instituciones universitarias y museísticas de Nueva York y Boston, o diferentes centros universitarios (Rutgers, Wisconsin, Albany, etc) fueron citadas por varios concursantes. Finalmente también Iberoamérica a donde han ido para completar su formación algunos licenciados, destacando en especial los becarios del ICl que se han dirigido a estudiar en Quito (FLACSO; en donde se citó explícitamente el magisterio de John Murra) o la UNAM de México (por ejemplo, el Instituto de Investigaciones Estéticas de dicha universidad).

La estancia en el extranjero ha sido generalmente financiada por becas españolas, sobre todo del Ministerio de Educación y Ciencia o del Instituto de 
Cooperación Iberoamericano. Algunos han tenido también becas de instituciones extranjeras, debiendo citarse especialmente las del Comité Conjunto Hispano Norteameicano y las del British Council. Un cierto número de los que se han desplazado al extranjero han conseguido diplomas durante sus estancias (como el Diploma de. Estudios Avanzados,DEA, en Francia) . Otros han aprovechado para efectuar excavaciones en colaboración con equipos internacionales o para realizar en los archivos extranjeros investigaciones para sus temas de investigación. En ocasiones la primera estancia de estudios ha sido seguida de otra posterior en la que se han podido obtener puestos de "Fellowship", "Associate Researcher" u otras equivalentes, integrándose así de una manera más activa en los equipos de investigación existentes.

Fueron muchos los concursantes que valoraron explicitamente la incidencia de esas estancias en centros extranjeros desde el punto de vista de la renovación metodológica y para dar nuevos enfoques y perspectivas a las investigaciones que realizaban. En conjunto, no cabe duda de que esa etapa en el extranjero ha sido algo decisivo en la formación de los investigadores. Aunque también queda mucho por hacer. En especial, sería conveniente disenar una política científica para diversificar las relaciones internacionales: Alemania, Rusia, Escandinavia, Países iberamericanos, Australia, Japón y China deberían entrar en los circuitos frecuentados por los licenciados españoles.

Desde el punto de vista de la integración en equipos de investigación, da la impresión de que hasta este momento la tendencia ha sido que los españoles se integren en equipos internacionales que tienen proyectos concretos: unas veces han ido a aprender, o bien aportan datos a programas internacionales en marcha; por ejemplo de creación de series climáticas internacionales. Tal vez sea el momento de pasar a una nueva fase en la que los equipos españoles tengan la iniciativa e integren a investigadores de otros países. Existe ya la masa crítica necesaria para ello, y de hecho está ocurriendo con la incorporación de investigadores iberoamericanos a equipos españoles. Vale la pena insistir en la necesidad de apoyar esa vía y, de forma especial, a los equipos que han recibido en los últimos diez años investigadores extranjeros, y que han producido ya resultados concretos de investigación en forma de tesis doctorales o publicaciones.

Tras la beca postodoctoral, el investigador vuelve generalmente a España y comienza la búsqueda de nuevas vinculaciones. Los caminos son diversos. En general, las becas de reincoporación permiten alargar un poco mas la situación de privilegio y continuar la investigación emprendida. Pero cuando se acaban esas ayudas los problemas vuelven a aparecer. Entonces se abren varias posibilidades.

Algunos se dedican a la enseñanza de nivel secundario $y$, a veces, universitario y se esfuerzan por mantener una colaboración eventual en equipos de investigación españoles. Los cursos de postgrado y las universidades públicas y privadas ofrecen recientemente algunas posibilidades y son varios los concursantes que tienen o han tenido plazas de asociados en ellas, y que han dado cursos en el extranjero, especialmente en centros superiores iberoamericanos. 
También existe la posibilidad, que algunos han utilizado, de colaborar como tutores en cursos españoles de universidades extranjeras. Otros encuentran un camino profesional eventual en los trabajos de documentalista, en la catalogación de libros y documentos, catalogación del patrimonio, inventarios arqueológicos, inventarios del patrimonio de museos (Museo del Prado, Calcografía Nacional, Academia de Bellas Artes, Jardín Botánico, Museo Lázaro Galdeano). Mención aparte merece la organización de exposiciones que en una década de grandes celebraciones ha podido ocupar a cierto número de investigadores con buenas relaciones sociales.

Existe también la posibilidad de integrarse al CSIC en calidad de investigador asociado o contratado, situación en la que se encuentran un buen número de los concursantes. Algunos citaron su colaboración en actividades propias del Centro de Estudios Históricos, bien sea integrados en los equipos de investigación, generalmente proyectos colectivos cuyo investigador principal es algún investigador del CSIC, o bien en tareas diversas (administrativas, de catalogación o documentación y otras, a veces poco brillantes y difíciles luego de calificar). En todo caso, se trata siempre de formas precarias que pueden combinarse con alguna de las anteriormente citadas, y que permiten la continuidad de la investigación y la difusión de la misma a través de congresos y revistas.

Todos los concursantes tienen entre sus méritos una amplia participación en congresos, coloquios y reuniones científicas. Estos encuentros han proliferado durante las décadas de 1980 y 1990 y han permitido el debate intelectual y la difusión de los trabajos que se realizan. Se trata de un hecho que hay que valorar, de forma general, muy positivamente. De todas maneras, existen diversas modalidades de participación: desde la simple presencia a la presentación de comunicaciones o a las ponencias y conferencias por invitación. Son asimismo varios los concursantes que han realizado actividades de organización de congresos o de simposios, dentro de congresos nacionales e internacionales (entre otros algunos tan importantes como Congresos Internacionales de Ciencias Históricas o de Historia de la Ciencia). La valoración de estos méritos se presta a debate, y necesita de criterios bien definidos que tengan en cuenta las distintas modalidades posibles de participación. Sobre todo, teniendo en cuenta que la participación en reuniones cientificas de los mas jovenes se ve asimismo afectada por la situación personal y familiar del investigador, así como por las relaciones sociales que le permiten el acceso a recursos públicos o privados.

\section{La presentación de los méritos}

La presentación de los méritos por parte de los concursantes se hizo de acuerdo con dos estilos diferentes. Uno consiste en la presentación lineal cronológica, en la que se expone la historia académica e investigadora y se relacionan las actividades y publicaciones que sucesivamente se realizan. Otro 
pone mas énfasis en el programa de investigación y en la evolución intelectual y prescinde -en algun caso casi totalmente- de cualquier referencia biográfica, considerando que el tribunal ya tiene los datos básicos en los curriculos que se han presentado.

Durante la prueba el tribunal tuvo ocasión de escuchar rotundas expresiones de autovaloración que, en general, estimo que estaban bastante justificadas. Algunos afirmaron que creían aportar una línea de investigación novedosa en su campo específico, lo que generalmente correspondía también a la realidad. Pudimos oir asimismo declaraciones de compromiso con la renovación científica y con la realización de una obra personal basada en la tensión y el esfuerzo reflexivo.

Varios concursantes hicieron constar tambiên de forma explícita su vinculación creciente con la comunidad científica internacional y alegaron que su trabajo es reconocido a escala internacional o en los países sobre los que trabajaban, lo que se reflejaría en el eco de sus publicaciones, o en el hecho de haber sido llamados a impartir cursos en centros extranjeros.

Estoy seguro de que, en general, esas declaraciones pueden aceptarse en el caso de esta oposición. Pero sin duda plantean un problema mas amplio: el de la necesidad de criterios de medida para que no queden al arbitrio de la interpretación subjetiva.

Fueron varios los opositores que hicieron al final de su exposicion inicial valoraciones globales de su actividad. Esos resúmenes eran siempre impresionantes porque mostraban de forma sintética la elevada calidad de los investigadores que se presentaron. A título de ejemplo, el resumen realizado por uno de los concursantes señalaba: " 13 años de actividad investigadora (algunos de ellos en centros extranjeros), 2 libros, 1 libro como editor, otro en elaboración, 25 artículos en revistas científicas, 23 ponencias en congresos, 12 estancias en el extranjero, 3 cursos especializados dirigidos, 6 proyectos de investigación financiados". Otros afirmaron llevar 18, 20 y mas años años investigando. Era dramático ver a esos excelentes y experimentados investigadores teniendo que opositar a una plaza que la mayoría no obtendrían. Es verdaderamente injusto que investigadores con casi tres décadas de experiencia, en las que han realizado una labor muy meritoria, no hayan alcanzado ya una estabilidad laboral en la institución a que han dedicado su trabajo y hayan de realizar esa oposicion para obtener un puesto fijo, que a pesar de todo no consiguen alcanzar.

La exposición de los concursantes fue seguida siempre de un debate con el tribunal. Creo que vale la pena destacar la calidad y el interés de las respuestas que se dieron a las preguntas efectuadas. El concurso mostró también algo digno de destacar como es la gran personalidad y la confianza en sí mismos y en su obra que mostraron un buen número de los participantes. Varios no dudaron en disentir abiertamente del tribunal y discutir con ellos cuando era necesario. Ante opiniones o preguntas de los miembros del tribunal algunos no dudaron en discrepar abiertamente, a veces con expresiones rotundas del tipo: "no comparto su apreciación sobre ese tema», y otras similares. Se trata de una actitud que el tribunal valoró siempre de forma muy positiva. Los

Hispania, LVIJ/1, nủm. 195 (1997) 305-327 
investigadores mas jóvenes han estado en contacto con equipos internacionales, se sienten científicamente seguros y no están cohibidos, por lo que no dudan en discutir o disentir. A veces se sucitaron debates abiertos entre los concursantes y los miembros del tribunal, y no se abrieron entre los mismos miembros del tribunal -sobre metodología, opciones teóricas o interpretaciones- porque el presidente, con buen criterio, los cortó recordando que no era ese el objeto de la reunión.

\section{Ramificaciones de los programas de investigación y publicaciones}

El estudio de los factores que influyen en las ramificaciones y bifurcaciones en los programas de investigación individuales y colectivos es un tema importante al que convendría prestar atención. Simplificando al máximo, hay dos modelos extremos. En uno existe desde el principio un claro proyecto intelectual que se desarrolla con continuidad y en el que las direcciones de investigación se deciden en función de los nuevos problemas científicos que aparecen. En otro el programa evoluciona en relación con factores sociales: oportunidades de integración en equipos, encargos que se reciben, contratos, empresas editoriales etc. Naturalmente, entre ambos podrían señalarse diferentes situaciones intermedias.

En nuestro caso, fueron numerosos los concursantes que realizaron una presentación articulada del desarrollo de su proyecto intelectual en la que lúcidamente destacaron la variedad de los factores que han influido en el mismo (becas, oportunidades, búsqueda consciente. etc). En general, los investigadores trataron de justificar las bifurcaciones de sus líneas de investigación en términos de evolución intelectual, aunque eran conscientes también del peso de los factores sociales en ese proceso de continuidad y cambio. Creo que la mayoría se daban cuenta de que la evolución de su proyecto de investigación se había visto afectada por los avatares aleatorios de becas, contactos, actividad profesional, encargos de libros, catálogos de exposiciones, y otros. Fueron varios los que valoraron explícitamente los congresos como lugar de encuentro y estímulo intelectual. En conjunto, da la impresión de que la necesidad de hallar nichos institucionales y, por consiguiente, de adaptarse a equipos consolidados y programas ya en marcha, afecta de forma decisiva a los investigadores mas jovenes, y a los que tienen un estatuto profesional menos consolidado.

En lo que se refiere a la evolución de los temas de investigación histórica, parecen existir dos itinerarios básicos. Unas veces es el problema el que guía la investigación, que puede perseguirse de forma diacrónica, aunque ello suponga pasar de un siglo a otro, por ejemplo, desde el estudio de las relaciones políticas del XIII a las mismas en el XV, aunque solo excepcionalmente de una edad a otra. Otras veces, el investigador se sitúa en un siglo determinado y selecciona diferentes problemas dentro del mismo, en un itinerario que puede conducir, por ejemplo, desde la política al arte, o viceversa, o desde la historia social a la historia económica o la historia de la ciencia, por citar 
algunos que efectivamente se realizaron. En algunos de estos itinerarios el papel de determinadas personalidades o equipos ha podido ser importante: a título de ejemplo, algunos concursantes pasaron desde la historia de América a la historia de la ciencia, por la influencia del programa movilizador dirigido a comienzos de los ochenta por el Prof. José Luis Peset.

La continuidad o cambios en los programas de investigación individual tiene un claro reflejo en las publicaciones, y puede dar lugar a estrategias diferentes a la hora de justificar el curriculum. Si se trata de un curriculum disperso el concursante siente la necesidad de insistir en su continuidad y coherencia. Si está muy concentrado (a partir de una Tesis y sus derivaciones), puede sentirse inclinado a mostrar que, a pesar de todo, se interesa por problemas diversos.

\section{Los programas de investigación}

Prácticamente todos los concursantes estaban vinculados de una u otra forma al CSIC. Solo unos pocos procedían de instituciones distintas y deseaban incorporarse al CSIC, tal vez como alternativa a otras salidas cerradas en la universidad.

El número de los concursante y sus orientaciones da una idea de la actividad de los distintos equipos de investigación que funcionan en el CSIC. Las presentaciones que se realizaron en el primer ejercicio ofrecieron un rico panorama de los programas que se desarrollan en estos momentos en los diversos campos de la historia dentro del Consejo. Esas informaciones fueron luego completadas con las exposiciones de los temas de investigación que se presentaron en el segundo ejercicio. Aunque prácticamente todos los concursantes superaron esa primera prueba, solo catorce de ellos decidieron participar en la segunda. Mas adelante citaremos de forma explícita los títulos de las investigaciones que éstos presentaron.

El panorama que puede obtenerse de las presentaciones que se realizaron es el de una investigación bien articulada a través de programas de investigación financiados por la CICYT, con directores eficaces y con problemas de continuidad del personal colaborador. Prácticamente todos reconocieron el magisterio de sus maestros. Entre los mas citados de la etapa universitaria José María Jover Zamora, referente explícitamente citado por varios opositores, y Guillermo Céspedes del Castillo, que algunos valoraron como el profesor que les dio una visión globalizadora de la historia. Entre los directores de equipos del CSIC se oyeron los nombres de Castroviejo, Delibes, Javier Arce, Ricardo Olmos, Sanchez Palencia, Julio Mangas, en prehistoria e historia antigua, de Reina Pastor en historia medieval, de Francisco de Solano en historia de América, de Manuel Espadas en historia contemporánea, o de José Luis Peset y Miguel Angel Puig Samper, en historia de la ciencia.

A partir de la información facilitada en las dos fases del concurso es posible presentar un panorama general de los problemas que están siendo investigados en los distintos Departamentos del Centro de Estudios Históricos del

Hisponia, LVIl/1, nu்m. 195 (1997) 305-327 
CSIC y de otros organismos ligados al Consejo. Es lo que intentaré hacer a continuación.

\section{La aplicación de nuevas técnicas y la renovación de la prehistoria}

En el campo de la prehistoria creo que debe destacarse, ante todo, el interés que ofrece la aplicación de nuevas técnicas para reconstruir la vida social y el medio ambiente en el que vivieron los hombres durante el proceso de hominización y la prehistoria. El autor de esta nota, alejado de esos campos de investigación, debe reconocer la fascinación que producen los trabajos presentados, al igual que los que se referían a la historia antigua y medieval.

Los temas objeto de atención son varios. Para empezar, el mismo proceso de hominización, al que se refirió Manuel Domínguez Rodríguez. Se ha planteado el problema de si la produccion de los restos en los yacimientos paleolíticos es siempre resultado de la acción humana o puede serlo del carroñeo de los homínidos, y en esa dirección se realizan trabajos en sabanas africanas para saber qué tipo de acción ha dado lugar a los restos existentes. El problema esencial es el orden de acceso de los homínidos a los animales, es decir la cuestión de si eran cazados por el hombre o carroñeados en competencia con otros carnívoros; a lo que se une otro secundario, a saber: si los yacimientos donde se encuentran restos humanos eran permanentes o intermitentes. Como los patrones de ruptura de huesos de los carnívoros (con marcas de dientes) son diferentes a los de los homínidos, que emplean artefactos líticos y manipulan las carcasas de animales, se realizan estudios sobre comportamientos de carnívoros en sabanas africanas, y se pone a prueba experimentalmente la hipótesis del carroñeo, con resultados que parecen contradecirla.

El conocimiento de la tecnología de talla y del uso de instrumentos de piedra en el paleolitico y epipaleolitico, supone a veces realización de experiencias. A partir del uso de los útiles prehistóricos, reflejado, por ejemplo en el tipo de pulido de uso, puede llegarse al conocimiento de las prácticas de los grupos; así, la siega a ras de tierra indicaría el aprovechamiento de la paja. Por ello se pone énfasis en el estudio de técnicas artesanas actuales para entender las prácticas y el utillaje prehistórico o protohistórico. Eso conduce también al estudio etnográfico de prácticas actuales semejantes. A todo ello se refirio Juan José Ibáñez Esteve, el cual aludió también a las estrategias económicas de los grupos sociales en la transición del palelítico al neolítico en la Península ibérica. Hasta el neolítico el saber técnico era general, y los especialistas actuaban dentro de la familia. Eso cambia en el neolítico pleno, cuando se desarrolla un comercio de materiales líticos, que se tallan con técnicas complejas y con utiIlaje especializado. Se produce una dicotomía en la concepción del utillaje: ciertos útiles de calidad se fabrican especializadamente, mientras que los mas corrientes se producen de forma mas amplia. De esta forma se concentran conocimientos que antes eran mas generales, a la vez que se produce una redistribución geográfica. Todo lo cual se refleja claramente en algunos yacimien. tos: si en los niveles inferiores se encuentran no solo el utillaje sino los objetos 
para su fabricación, en los superiores aparecen solo los útiles sin los objetos para fabricarlos, lo que mostraría la especialización técnica.

Las investigaciones sobre la prehistoria y protohistoria se han visto afectadas por el desarrollo de la paleometalurgia, y la elaboración de vastos bancos de datos a partir de análisis químicos y metalográficos de todos los restos metálicos que se, han hallado en los yacimientos. A partir de esos estudios se está reevaluando el origen de la metalurgia en el Sureste peninsular. Los datos disponibles hoy, y en especial los análisis realizados en yacimientos costeros de la provincia de Almería, parecen mostrar que hay un proceso de innovación autóctono, con ausencia de especialistas a tiempo completo, según explicó Ignacio Montero Ruiz. La organización de las sociedades agropastoriles del neolítico cambia en la edad del bronce, cuando el acceso a los recursos se hace mas selectivo y jerarquizado y una parte de la población pasa a ser dependiente de otra, lo que se refleja en el hecho de algunos se entierran con ricos ajuares y otros no. Los grupos sociales ya no aparecen organizados en bandas o tribus, sino en organizaciones con jefaturas; se especializan las armas y aparecen las construcciones fortificadas, a la vez que se inicia un proceso hacia una mayor complejidad social, que conducirá a la constitución de unidades políticas estructuradas. Tradicionalmente se ha atribuido un papel determinante a la metaluria en la transformacion económica y social. Pero algunos creen hoy que en ciertas situaciones la metalurgia no pudo desempeñar ese papel, debido a pequeña escala en que se realizaba y al amplio acceso de muchos a dicho recursos en áreas con grandes riquezas minerales. Sería mas bien el aprovechamiento agrícola de los terrenos lo que se convertiría en un elemento de jerarquización social. En lo que respecta al desarrollo de la metalurgia en el Sureste de la Península ibérica, algunos cuestionan hoy el difusionismo a ultranza y se valora el desarrollo autóctono. Esa tesis fue defendida por Ignacio Montero en su exposición sobre Los inicios de la metalurgia en la Peninsula iberica a la luz de los nuevos descubrimientos de Cerro Virtud (Cuevas de Almanzora, Almeria).

El tema de la difusión de la metalurgia se planteó igualmente en otra exposición, la de Pablo Gómez Ramos. En el marco de un amplio programa de estudio de arqueometalurgia de la Península iberica, desarrollado en el CSIC, se está profundizando en las características de la metalurgia hispana desde el calcolítico y en las cuestiones de difusión y estabilidad de las técnicas de fundición, así como en el conocimiento de la tecnología de la fundición de metales en la prehistoria y protohistoria.

En los debates que siguieron a las exposiciones de los Drs. Montero y Gómez se planteó el problema del papel de las técnicas en la evolución social, y se defendió la necesidad de replantear el papel de la tecnología como factor fundamental. También se suscitó el tema de la aplicación de la tecnología metálica a la agricultura. En ese sentido se destacó que en el mundo argárico hay muchos elementos metálicos personales, tales como punzones o hachas ceremoniales, pero ningún elemento que se pueda vincular con la actividad agrícola, los cuales solo aparecen en el bronce final, cuando se encuentran las primeras hoces metálicas.

Hispenia, LVIU/1, núm. 195 (1997) 305-327 
Otra interesante línea de investigación es la de los estudios paleambientales, que se asocian al desarrollo de la agricultura y a los posibles procesos de degradación del medio ambiente como resultado de la acción humana. El estudio de las semillas halladas en yacimientos arqueológicos se ha convertido en un tema relevante. A ello se refirió la exposición de Carmen Cubero Corpas. Dichos estudios permiten conocer las relaciones entre agricultura y alimentación, la posibilidad de rotaciones de cereales y leguminosas, y la difusión de los cultivos arbustivos y arboreos. El conocimiento de las malas hierbas, orienta sobre los tipos de cultivo o las técnicas aplicadas y, en definitiva, sobre el conocimiento técnico. En general, se trata de estudiar con detalle el proceso de domesticacion de las plantas, que puede prolongarse a veces durante un período de hasta 200 años. En ocasiones dichas investigaciones van unidas a la relectura de aquellos textos clásicos en los que existen alusiones a recursos agrícolas de la Península ibérica. La investigación de Carmen Cubero sobre La paleocarpología y la agricultura en la antiguedad. El valle del Ebro en la Edad de Hierro, nos permitió conocer los resultados mas recientes obtenidos en los yacimientos de esa región.

\section{Nuevos enfoques en historia antigua}

Los estudios de historia antigua también se benefician de nuevos enfoques interdisciplinarios a viejos temas de investigación. La arqueología del paisaje, la cartografía histórica, la relectura de las fuentes clásicas y la iconología se encuentran entre las nuevas orientaciones utilizadas por algunos investigadores presentes en el concurso.

Los estudios de arqueología del paisaje romano han recibido un importante impulso con el programa de investigación que se desarrolla en el CSIC sobre la zona arqueológica de las Médulas (León), donde se explotó una mina de oro gestionada por el Estado romano. El análisis de los restos de dicha explotación permite profundizar en las relaciones entre estructura social y territorio. Además del conocimiento de la propia actividad minera, puede avanzarse en el de las transformaciones que ésta generó en el mundo indígena. Aunque existen ejemplos de continuidad de las formas de vida de las comunidades locales indígenas, también hay datos de cambios importantes, por modificaciones en el acceso a los recursos, apropiados por los romanos, y cambios en el poblamiento y en la morfología de los castros. Pueden reconstruirse los desfases culturales entre las comunidades locales y el mundo romano y los conflictos que aparecen entre las comunidades indígenas por el acceso a los recursos. Los estudios que se realizan ponen énfasis en los mecanismos de incorporación de las poblaciones indígenas al mundo romano. Almudena Orejas Saco del Valle ha dedicado atención a todos esos temas, dentro de su línea de investigación sobre el paisaje antiguo como creación cultural, y presentó en el segundo ejercicio un sugestivo trabajo acerca del tema Metalla en la Península ibérica. Algunos aspectos sobre su organización territorial. 
Una tarea esencial en las investigaciones que se realizan es la finalización de la Tabula imperii Romani, mapa del imperio romano a escala 1:1.000.000, iniciado en 1929 y todavía inacabado en la parte correspondiente a Hispania. Ese trabajo incluye también la elaboración de un elenco topográfico, enumeración de pueblos indígenas, accidentes geográficos y la toponimia grecolatina no localizada. Se trata de un instrumento esencial para sistematizar espacialmente la información existente y punto de partida para otras investigaciones, ya que puede permitir, por ejemplo, elaborar modelos de asentamiento y organización del territorio. De esa cartografía histórica pudimos tener noticias gracias a las intervenciones de dos de las concursantes, una de las cuales, Adela Cepas Palanca, actúa como secretaria del comité de redaccion de la Tabula. La Dra. Cepas en su investigación sobre La ciudad hispanorromana en época tardía, realizó una reevaluación de la crisis del siglo III, y manifestó dudas sobre su existencia tras reexaminar las fuentes y la documentación.

El estudio de la organización del ejército romano está recibiendo también nuevas aportaciones. A ello se refieren la tesis doctoral y las investigaciones que realiza otro de los concursantes Sabino Perea Yébenes, sobre las asociaciones militares en el imperio romano, especie de asociaciones de oficiales que cumplieron funciones diversas.

El estudio del mundo romano se enriquece con aproximaciones novedosas, que incluyen, por ejemplo, interpretaciones icónicas a partir de la teoría de la comunicación. Mito, religión y política estaban profundamente interrelacionados en el mundo antiguo, y el poder político se sirvió conscientemente de ello. Ese es el campo a que se refieren las investigaciones de Fabiola Salcedo Garcés sobre la iconografía de las provincias romanas del occidente, con énfasis especial en la iconografía de Africa. En ellas se aborda, de alguna manera, el tema del poder, a través de la iconografía que modela e impone, es decir a través de la creación de símbolos visuales como garantes del poder. Los problemas de la aculturación de las sociedades indígenas, y la interacción de pueblos dominantes y dominados fueron abordados en la exposición de esta autora sobre Imagen, persuasión y poder. Usos de la aculturació e iconografía oficial romana, en una aproximación que puede ser de interés también para el estudio de otros procesos de aculturación, como los de las sociedades indígenas americanas durante el período colonial español.

La reevaluación de la historiografía arqueológica está siendo realizada por Maria Gloria R. Mora Rodríguez. Su tesis doctoral sobre la arqueología clásica en España durante el siglo XVIr, constituye a la vez un estudio de la anticuaria y de la manipulación de datos arqueológicos, y ofrece un gran interés para el tema de la recepción del clasicismo en España. El estudio y protección del patrimonio arqueológico español adquiere nuevas dimensiones en el XIX, siglo en el que se inicia también el proceso de profesionalización de la arqueología. Los trabajos de la Dra. Mora conducen a una reevalución de la arqueología espan̄ola y proporcionan una nueva imagen de los estudios sobre la antiguedad en España, mas rica de lo que se pensaba y comparable, en muchos aspectos, a la producción extranjera. Por ejemplo, el repertorio de 12.000 inscripciones de Candido María Trigueros, del que se aprovechó Hübner, o las 
LA INVESTIGACIÓN HISTÓRICA EN ESPAÑA A TRAVÉS DE UNA OPOSICIÓN DEL CSIC 319

colecciones numismáticas de españolas de los siglos XVIII y XIX suponen iniciativas plenamente comparables a las que se adoptaban contemporáneamente en otros países europeos.

\section{Viejas y nuevas preguntas en Historia medieval}

De manera similar a lo que acabamos de citar, las investigaciones mas recientes en el campo de la historia medieval desmienten la idea de excepcionalidad de la corona de Castilla como resultado de la Reconquista. Investigaciones como la que presentó Ana María Rodríguez López realizan un análisis comparado de las monarquías hispanas con otras europeas, sin partir de la diferencia, sino aceptando desde el comienzo la similitud.

En los últimos años han surgido nuevos interrogantes sobre la edad media, que han conducido a la necesidad de reinterpretar la historiografía tradicional en lo que se refiere, por ejemplo, a las relaciones entre monarquía, eclesiáticos y nobles. Hoy se acepta que existe una interdependencia entre el proceso de expansión territorial de Castilla y la consolidación de la monarquía, y que ésta es similar a la de otras monarquías feudales. Temas abordados en la investigación de Ana María Rodríguez López son la diferenciación de las sociedades medievales, la interacción social, la evolución de las comunidades campesinas y la acción monástica, con el estudio de las diversas modalidades de foros y contratos, y la reinterpretación de las fuentes conocidas, planteando nuevas preguntas a los documentos. La exposición de la Dra. Rodríguez sobre La evoLución del Foro romano y del Palatino en la Edad media. El ejemplo de los asentamientos nobiliarios fue un excelente ejemplo de esos nuevos enfoques de la historia medieval en donde la reinterpretación de la documentación archivística y el trabajo de campo permiten encontrar respuestas novedosas a preguntas importantes en el campo de la historia urbana medieval.

En la historia de la edad media, como en la de otros períodos, muchas veces mas que nuevos documentos lo que se necesitan son nuevas preguntas y nuevos métodos. Gran interés ofrecen en ese sentido las recientes investigaciones sobre historia de las instituciones medievales, que superan la tradicional línea legal jurídica y que intentan reconstruir el aparato del poder desde la historia social. Un buen ejemplo de ello pueden ser las investigaciones de una de las concursantes, María Cristina Jular Pérez, que se refieren a la organización administrativa y territorial del reino de León en los siglos XIII al xV, a través de los funcionarios reales y sus relaciones con la estructura feudal. Su interés se dirige a los diferentes niveles de funcionarios regios. Ante todo, los adelantados o merinos mayores, que constituyeron el tema de su tesis doctoral; y mas tarde, otros funcionarios de menor rango. Precisamente a uno de esos grupos dedicó esta concursante su investigación en el segundo ejercicio, Los prestameros del rey. Estructuras feudales en la Castilla de los siglos XII y XIV. En el debate de las exposiciones de esta autora aparecieron temas recurrentes sobre la definición del poder, en el sentido de si ha de entenderse como pura coerción, o coerción mas consenso o, en el caso de la sociedad medieval, 
coerción mas rivalidades familiares, y el interés de profundizar en el estudio de la media y baja nobleza, poco conocida todavia en lo que se refiere a Castilla medieval. También se suscitó el sentido de la expresión "clientela» y cliente, que la autora caracterizó no como una simple metáfora sino como una relación entre poderosos, algo mas laxa que la feudal vasallática, pero que sigue siendo una relación de poder, con contenido político.

\section{Reinterpretaciones y enfoques comparativos en Historia moderna}

El período de estancamiento y decadencia que constituye el siglo xvII hispano, objeto de estudios tan renovadores de historiadores ingleses y norteamericanos, está recibiendo una renovada atención por parte de los historiadores españoles. En esa nueva línea es de destacar la investigación que realiza Rafael Valladares Romero sobre las consecuencias que tuvo la separación de Portugal para la Monarquía hispana. Se trata de un investigación muy novedosa que rompe con la escasa atención dedicada tradicionalmente a la separación de Portugal por historiadores españoles, olvido que se relaciona, a su vez, con toda una serie de razones, tales como el escaso interes de la historiografía nacionalista sobre la decadencia, las estrategias desvalorizadoras de la historiografía borbónicas sobre el período de los Austrias o la desvalorización del período absolutista por parte de los historiadores liberales. La investigación del Dr. Valladares sitúa esos procesos en el contexto de la evolución europea, acudiendo para ello personalmente a los archivos extranjeros y realizando comparaciones entre el imperialismo hispano y el de otras potencias de la época como Francia o Suecia. En su exposición sobre $L a$ monarquía hispana y el Portugal de los Braganza en el siglo XVII (1640-1700) mostró el peso decisivo que tuvo la incorporación y la separación de Portugal sobre el crédito y sobre los recursos de la Monarquía Universal Española.

Nuevas aproximaciones se realizan también al problema de las relaciones entre los distintos reinos hispanos durante la edad moderna. A ello se refirio otra de las concursantes, Ana Mercedes Azcona Guerra, que centra su atención en las existentes entre Navarra y los restantes reinos peninsulares, así como con las provincias del sur de Francia. El estudio de las reformas ilustradas en Navarra se sitúa por esta autora en el marco de un contexto social en el que se consideran el papel de los grupos mercantiles interesados en el mantenimiento o supresion de las aduanas interiores, las redes sociales tejidas por los navarros en Madrid, y las estrategias de las diferentes colonias mercantiles, entre otros, todo lo cual le ha conducido finalmente a a interesarse por cuestiones referentes a la historia marítima y a las relaciones entre puerto y ciudad.

\section{Una nueva atención a la historia contemporánea de España}

En el campo de la historia contemporánea parece dedicarse una nueva atención a las relaciones diplomáticas, aunque situándolas ahora en el con- 
texto global de las relaciones internacionales y de la lucha de proyectos imperialistas. En el caso español, se presta atención a dos ámbitos geográficos concretos: el Mediterráneo y los conflictos entre potencias que se asoman al mismo, y el Pacifico en el contexto del imperialismo europeo y el naciente imperialismo norteamericano.

Existe hoy un renovado interés por las conexiones entre la politica exterior española y la política internacional, así como un esfuerzo para situar la historia de España en un contexto internacional sin tratar de justificar la decadencia o la depedencia. En esa línea María Dolores Elizalde Pérez-Grueso estudia la participación de España en las relaciones internacionales a finales del siglo XIX, prestando atención preferente a la expansión imperialista norteamericana en el Pacífico y su impacto sobre los restos del imperio español en Asia (Filipinas, Carolinas, Marianas y Palaos), en el marco de las modificaciones geopolíticas producidas por los conflictos sobre el control de las líneas de comunicación, los nuevos problemas migratorios, el acceso a los recursos y a los mercados o la creación de imagenes imperiales. Sobre todo ello habló también la Dra. Elizalde Perez-Grueso al presentar, en el segundo ejercicio, su trabajo De nación a imperio: la expansión de los Estados Unidos por el Pacífico en 1898.

Por su parte otro investigador, Fernando García Sanz, centra su atención a las relaciones entre España e Italia desde el siglo XIX, en una investigación que sitúa igualmente las relaciones diplomáticas en el contexto mas general del desarrollo económico o cultural. Existe, en ese sentido, un esfuerzo para buscar fuentes que permitan abordar los nuevos problemas. Entre ellos el papel de las imágenes y de los estereotipos sobre los países en las relaciones políticas. Estas cuestiones fueron nuevamente abordadas en su exposición sobre Una visión mediterránea de la Primera Guerra Mundial: entre neutralidad y beligerancia. España e Italia 1914-1918.

Otro concursante, Pedro Barruso Bares, presentó sus investigaciones sobre la historia contemporánea del País Vasco, especialmente las elecciones durante la Segunda República, los origenes del socialismo y el movimiento obrero en Guipuzcoa, la justícia durante la guerra civil o el componente clerical en la política vasca. El Dr. Barruso dedica también una parte de su esfuerzo investigador a desmentir una serie de mitos de la historiografía vasca que tienen influencia en la vida politica actual.

\section{Catalogación y nuevas preguntas en historia del arte}

El esfuerzo de catalogación e investigación documental y bibliográfica del patrimonio artístico español es una labor benemérita que resulta esencial para poder iniciar otros estudios. Se trata de una línea tradicional e imprescindible en el campo de la historia del arte, a la que algunos investigadores han dedicado un valioso trabajo. Una concursante, María Luisa Tárraga Baldo, presentó un amplio muestrario de dicha tarea, a la vez que sus estudios sobre el arte cortesano español del siglo XVII; esos trabajos permiten 
valorar producciones escultóricas hasta ahora poco estimadas, pero de gran relevancia, interpretando el programa iconográfico en el que se sitúan, asignando las autorías, y elevándose a apartir de ahí al problema mas general de las relaciones artísticas entre España y otros países, especialmente Italia, durante el setecientos. Estas investigaciones, y el análisis de la documentación histórica sobre mármoles y rocas, son también de gran importancia para resolver problemas de restauración y conservación del patrimonio artístico y monumental.

La atención sistemática a otros temas, como la historia del grabado, es relativamente reciente en nuestro país. Y mas aún las investigaciones sobre el desarrollo histórico de las técnicas para la producción de las imágenes seriadas. A ello dedica atención María Jesús Vega González, que ha realizado valiosas aportaciones al desarrollo de la imprenta en España, y a la difusión de las técnicas de impresión, como la litografía y la calcografía. A partir de ahí ha realizado también investigaciones sobre la difusión de grabados en los medios populares, por ejemplo a través de revistas para la clase media, y por las innovaciones en las técnicas de reproducción de imágenes (esencialmente la fotografía) que afectaron profundamente al grabado. La Dra. Vega ha pasado posteriormente a interesarse por las imágenes de la arqueología y el mundo antiguo en el siglo XIX. A ello se refirió su interesante exposición en el segundo ejercicio, sobre el tema La imagen de la Antigüedad en la Inglaterra Victoriana. La cultura asiria recuperada y difundida a través de la prensa.

En el campo de la historia del arte contemporáneo otro concursante, José Miguel Cabañas Bravo, está estudiando problemas de museología, mecenazgo, y coleccionismo en el arte español de los siglos XIX y XX, con especial atención al arte español antes y despues de la guerra civil, así como al papel del arte en la políitica del franquismo. A esta última cuestió se refirió su trabajo de investigación, presentado en el segundo ejercicio, sobre La reorientación de un instrumento politico de politica exterior del franquismo. La transformación de las Bienales hispanoamericanas de Arte.

\section{De la historia de América a la historia de la ciencia}

La intervención de algunos concursantes muestra una interesante asociación entre la historia de América y la historia de la ciencia o de la técnica. El camino se ha recorrido en las dos direcciones, pero en todo caso ha conducido finalmente al cultivo simultáneo de ambos campos.

Un caso bien significativo es el de Manuel Lucena Giraldo, que puede citarse también como ejemplo de la forma en que se van produciendo las ramificaciones de un programa de investigación personal. Su evolución, tal como él mismo la presentó al tribunal, se ha realizado en varias etapas. Tras acabar sus estudios de licenciatura se interesó por el papel de la la geografía en la historia de América, las fuentes históricas americanistas, la conformación del núcleo colonial de Venezuela, y el papel del cacao y de la elite caraqueña en el mismo; mas adelante, pasó a interesarse por las reformas

Hispania, LVLI/, núm. 195 (1997) 305-327 
borbónicas en América, la transformación del espacio americano y la historia de las fronteras; con su incorporación al Departamento de Historia de América del CSIC pudo participar en la edición de las relaciones geográficas del arzobispado de Nueva España,y realizar su tesis doctoral sobre viajes y exploraciones científicas a la Guayana; en ella trató de mostrar que el verdadero efecto de esas exploraciones había que buscarlo en el espacio americano, considerando las citadas expediciones como una herramienta del reformismo borbónico. La atención a las expediciones de límites en la América del setecientos le condujo a estudir la ciencia para la frontera, la relación entre criollismo e ilustración, la utopía tropical de la Compañía guipuzcoana, y el papel de la botanica en las expediciones al Orinoco. De ahí llegó al estudio de algunas instituciones científicas, como el Jardín Botanico, y al de la racionalización de viejas utopías en la ocupación y organización de espacios marginales americanos durante el siglo xviu. Una beca postdoctoral le permitió estudiar en Gran Bretaña, donde profundizó en sus investigaciones sobre la colonización fronteriza, especialmente en las dimensiones demográfica y forestal, dirigiendo también su atención hacia la reconstrucción y análisis de nuevas fuentes; lo cual le permitió encontrar y editar los Axiomas politicos de Malaspina o estudiar la obra del naturalista Félix de Azara. Al mismo tiempo, trató de mostrar la continuidad de la política española en América después de la independencia. A su vuelta a España retoma viejos temas con nuevos enfoques: se interesa por el impacto del reformismo en Nueva Granada, estudia los diversos proyectos de organización espacial, centrados en Cartagena de Indias (como el canal del dique), el area oriental de Nueva Granada, y el ámbito selvático amazonico. Finalmente, una estancia en la Universidade Oxford y la relación con el profesor J. Elliot, le ha permitido iniciar a una reflexión global sobre el reformismo borbónico americano, en el contexto de las actuaciones ilustradas a escala mundial. En relación con esa nueva vía, su exposición en el segundo ejercico estuvo dedicada a El problema del clasicismo en las reformas borbonicas en América.

Una evolución similar ha tenido Leoncio Lopez-Ocón Cabrera, que desde la historia de América llego, de forma mas decidida, a la historia de la ciencia. Los primeros trabajos sobre catalogación de fondos americanistas del Archivo de Indias, y su estudio del periódico quincenal La America, le condujeron al estudio de las relaciones científicas entre España y Amérìca, y al papel de los científicos en la acción exterior de nuestro país. Su centro de interés fueron la figura de Marcos Jiménez de la Espada, la expedición al Pacífico y las redes de comunicación científica, $A$ partir de ahí nació su interés por la circulación internacional de la ciencia y el proceso de mundialización, con énfasis en la dimensión comunicativa de la ciencia, las redes sociales de interacción y el papel de las sociedades científicas americanas en la vertebración nacional de los países americanos independientes. Su atención creciente a la evolución de la ciencia espariola en la segunda mitad del XIX se reflejó en el trabajo de investigación que presentó al segundo ejercicio sobre El fomento de la educación y la ciencia en la sociedad española del Sexenio. 
Un itinerario diferente es, en cierta manera, el que ha conducido a otro investigador, Francisco Pelayo López, desde la historia de la ciencia a la historia de la ciencia americana. Desde hace años el Dr. Pelayo ha venido desarrollando una importante línea de investigación sobre la incidencia de las nuevas teorías científicas biológicas en el siglo XIX y sobre la historia de las ciencias naturales. Su labor ha contribuido, junto con la de otros investigadores de la Universidad Complutense (como Joaquín Fernández, del que fue discípulo) y del CSIC (como Miguel Angel Puig Samper) a abrir una notable línea de investigación en historia de la biología. Su contribución personal ha sido especialmente destacada en el estudio de fondos inéditos de la historia de la ciencia española y americana del xVIII y XIX, en el de las expediciones científicas y en especial la expedición al Orinoco, las biografias de científicos (Loeffling, Torrubia), la edición de obras de científicos españoles, historia de la paleontología.y al estudio de instituciones científicas españolas como el Real Jardín Botánico, cuyos fondos ha contribuido a catalogar y difundir. Sus trabajos mas recientes sobre historia de la geologia española de los siglos XVII y xvin iluminan parcelas hasta ahora poco conocidas de los origenes de esta disciplina, situándola en el contexto de la evolución científica internacional.

El espectacular desarrollo que ha tenido en los últimos decenios la historia de la ciencia ha conducido a la aparición de nuevos temas, a los que se dedican ahora notables esfuerzos intelectuales. Un ejemplo de esos nuevos enfoques fue la intervención de Luis Javier Moscoso Saravia cuyas investigaciones se han centrado en la teratologia o estudio de la deformidad fisica, la vez que en el examen y contextualización de las doctrinas vitalistas del siglo XVIII.

En este grupo de investigaciones sobre historia de la ciencia o de interés para ella podría incluirse también las referentes a climatología histórica que presentó otro de los concursantes, Mariano Barriendos Vallvé. La preocupación que hoy existe por reconstruir la dinámica climática en época histórica ha llevado a los intentos de elaborar series climáticas homogéneas y fiables. Una de las vías seguidas es la que se refiere a los episodios de precipitación extrema, tales como inundaciones, de los que puede encontrarse amplia información a partir de fuentes eclesiásticas y municipales (por ejemplo, series de inundaciones en areas concretas y de rogativas para impetrar la lluvia). El especial interes que tiene la dinámica meteorológica en la Península ibérica, en la encrucijada entre varios dominios climáticos, hace especialmente importantes estos estudios, que utilizan de forma imaginativa fuentes históricas tales como archivos municipales, parroquiales y señoriales, catastros, o documentación de instituciones científicas para extraer información fiable sobre las oscilaciones climáticas. Los modelos matemáticos que existen pueden incorporar datos empíricos, y sus resultados facilitar informaciones relevantes para la investigación histórica y para estudios aplicados (como, por ejemplo, la existencia de oscilaciones climáticas y las probabilidades de inundaciones catastróficas, de utilidad para el diseño de las obras públicas).

Hixpania, LVI1/1, núm. 195 (1997) 305-327 


\section{Problemas metódológicos y nuevos caminos para los historiadores}

Podemos hacer, para acabar, unas consideraciones generales sobre algunos problemas metodológicos y sobre la necesidad de buscar vías de aplicación a las investigaciones históricas.

Repetidas veces se escucharon durante las pruebas declaraciones sobre la importancia de la historia comparativa. Es posible, sin embargo que esta manida expresión no fuera usada por todos de la misma manera. Tal vez convendría ponerse de acuerdo sobre su sentido. Escuchando a algunos concursantes se podía tener la impresión de que ese interés por la historia comparada se había adquirido durante sus estancias en el extranjero, con ocasión de preguntas que allí les hicieron sobre la especificidad del caso español. En todo caso, vale la pena añadir que el estudio comparativo entre España y otros países parece abordarse hoy sin los complejos de inferioridad o de justificación que existían en el pasado, y aceptando plenamente la idea de la similitud con la evolución de otros países europeos.

También pudieron oirse numerosas declaraciones sobre el carácter interdisciplinario de las investigaciones que se realizan. Es cierto que pudo comprobarse en varias ocasiones que los historiadores parecen mirar con creciente interés hacia la antropología, la sociología, o la ciencia política, mientras que otros se dirigen hacia la geografía o hacia conocimientos técnicos muy especializados. La incorporación de esas dimensiones puede exigir en algunos casos debates teóricos y metodológicos, a los que dedican atención los jóvenes historiadores, como pudo verse en la exposición de méritos de algunos concursantes.

Sin duda ha de valorarse de forma positiva ese diálogo interdisciplinario, y puede defenderse la conveniencia de activarlo y ampliarlo, en beneficio de la investigación histórica. En particular, debería intentarse de una forma mas sistemática la aplicación a períodos del pasado de teorlas sociales elaboradas sobre la sociedad contemporánea. Aunque algún concursante manifestó de forma clara su voluntad de basar las investigaciones en el campo de la sociología (por ejemplo para el estudio de las redes de interacción científica) es mucho lo que todavía queda por hacer. EI CSIC debería estimular esos debates interdisciplinarios, tanto de forma general como con referencia a temas concretos. Por ejemplo, en relación con la definición y caracterización del poder, tema recurrente en muchas investigaciones históricas, podría explorarse la utilidad de teorías y conceptos desarrollados en la antropología o la sociología. De manera mas general, y por aludir a temas que fueron citados en las exposiciones, existen hoy teorías sociológicas económicas o geográficas que tal vez podrían utilizarse en las investigciones históricas sobre las redes sociales, la interacción entre grupos sociales, la organización del poblamiento, el desarrollo económico o los procesos de profesionalización.

Debemos insistir en la gran calidad y la importancia de las investigaciones que se realizan en los campos de la historia y las humanidades y en la conveniencia de establecer criterios de valoración que, siendo rigurosos, tengan en 
cuenta algunas especificidades de estas disciplinas científicas. Al mismo tiempo, convendría destacar con energía las funciones culturales y políticas esenciales que pueden tener las investigaciones en el campo de las humanidades y, mas concretamente, en el campo de la investigación histórica.

Habría que evitar, en todo caso, que el cientifismo naturalista y tecnicista que a veces domina entre los gestores de la política científica de nuestro país, considere la investigación en humanidades como campos que, por utilizar una expresión decimonónica, podrían considerarse "de adorno". Lo que podría resumirse en esa expresión atribuida a un gestor que al hablar de la política cientifica del país y de la conveniencia de invertir en ciencia y tecnología, no olvidaba nunca reconocer la necesidad de apoyar nuestras materias con la expresión: "cariñitos para las Letras".

Pero al mismo tiempo, debemos esforzarnos en encontrar vías de aplicación de nuestras investigaciones, sobre todo con vistas a los nuevos licenciados. Sin duda, es un auténtico dislate la política universitaria que ha convertido las Facultades de Historia, Arte o Filosofía - que deberían ser las mas selectivas, rigurosas y minoritarias en un pafs como el nuestro- en una especie de aparcamiento para estudiantes poco preparados y poco exigentes. Pero, dada la imposibilidad de cambiar a corto plazo esa situación, es preciso esforzarse por dirigir a estos licenciados hacia salidas profesionales diferentes a la enseñanza o la investigación. Y a los jóvenes investigadores orientarlos también hacia la aplicación práctica de sus investigaciones y de sus conocimientos.

Lo cierto es que las posibilidades que existen son mas numerosas de lo que se piensa, $y$ en este concurso tuvimos ocasión de comprobarlo repetidamente. Muchos concursantes han mostrado una capacidad para realizar con éxito una labor profesional en la organización y realización de exposiciones y de sus correspondientes catálogos; otros han dirigido la catalogación de fondos de museos o archivos, y muchos han demostrado que pueden buscarse con éxito nuevas vías para la difusión de los conocimientos científicos a través de televisión, video, radio, soporte electrónico y diversas formas de extensión cultural. Pero existen otras muchas posibilidades que también se han explorado y que convendria ampliar.

Es indudable que la colaboración del historiador es esencial para la puesta en marcha de políticas de conservación del patrimonio artistico y monumental, y efectivamente a ello se dedican crecientemente un cierto número de especialistas. En ese sentido es de destacar su colaboración en los aspectos patrimoniales de las zonas arqueológicas, el interés de la arqueología del paisaje para la planificación territorial, la importancia de la utilización en la investigación arqueológica de métodos no destructivos, tales como la teledetección, el uso de imágenes de satélites y sistemas de información geográfica. El historiador puede participar activamente en la gestión del patrimonio cultural, especialmente zonas arqueológicas que pueden convertirse en parques culturales.

Unos pocos han tomado ya iniciativas para organizar gabinetes de estudio de carácter privado, aprovechando la circunstancia de que algunas institucio-

Hispania, LY!U/L, núm. 195 (1997) 305-327 
LA INVESTIGACION HISTÓRICA EN ESPAÑA A TRAVÉS DE UNA OPOSICIÓN DEL CSIC 327

nes públicas desean disminuir el número de funcionarios y animan la constitución de empresas de servicios a las que les encargan los estudios que necesitan.

Pero podemos citar, además, otros campos en los que la labor del historiador puede ser muy importante y en donde existen posibilidades de empleo: los estudios de sismología y climatología histórica, la rehabilitación de los centros históricos de las ciudades, el asesoramiento a empresas en el campo de la documentación, la catalogación del patrimonio histórico de empresas concretas, la gestion de archivos de personal, o las redes informáticas. Esperemos, que de forma imaginativa, los directores de equipos de investigación puedan ir orientando a los nuevos investigadores hacia esos campos, al tiempo que el Consejo Superior de Investigaciones Científicas adopta las iniciativas necesarias para dar estabilidad en el empleo a aquellos que ya ha contribuido a formar con una importante inversión económica realizada durante las dos últimas décadas. 